\title{
Afinal de Contas Quem Sou Eu? Ah, Este é o Grande Enigma!': (Re)negociação de Significados na (Des) construção do Nexo Identitário como Professora- Pesquisadora que Ensina sobre Ciências ${ }^{2}$
}

\section{After all, who am I? Oh, this is the big puzzle!: (re) negotiation of meanings in the (de) construction of the identity nexus as a teacher-researcher who teaches about Sciences}

\section{Patrícia Petitinga Silva ${ }^{\circledR}$ Brasil Andréia Maria Pereira de Oliveira ${ }^{\circledR}$ Brasil}

Nosso objetivo é a compreensão da identidade tanto como nexo de multifiliação, quanto conciliação das distintas formas de afiliação a comunidades sociais para entender como a (re)negociação de significados forja um nexo identitário como professora-pesquisadora que ensina sobre ciências. Essa é uma investigação qualitativa em que adotamos como dispositivo de investigação a história de vida, sendo a narrativa autobiográfica utilizada como fonte para a produção dos dados, os quais foram analisados segundo o constructo de identidade na prática, proposto por Jean Lave e Etienne Wenger. Para ajudar-nos nessa análise, fazemos uma interlocução com as Aventuras de Alice no País das Maravilhas e Através do Espelho, evidenciando o mérito do diálogo entre ciência e arte para a produção de conhecimentos. Uma vez que pertencemos a várias comunidades sociais, (re)negociamos maneiras de ser um membro em cada uma delas, (des)construindo uma identidade de afiliação, assim como criamos meios de continuidade entre essas comunidades mediante a reconciliação identitária.

Palavras-chave: identidade; negociação de significados; professora-pesquisadora; nexo identitário; ensino sobre ciências.

$1 \mathrm{O}$ título é o que Alice diz para si mesma depois de ter experienciado coisas esquisitas ao despencar pela toca do Coelho, capítulo 2 - A lagoa de lágrimas - do livro "Aventuras de Alice no País das Maravilhas" (Carroll, 2013, p. $17-18)$.

2 De acordo com Carvalho (2004), uma das modificações propostas nos objetivos da educação científica, desde as últimas décadas do século XX, diz respeito ao entendimento do conceito de conteúdo escolar, que passou a conjugar as dimensões conceitual, formativa e cultural para a aprendizagem disciplinar. Nesse sentido, recomendase que o ensino de Ciências ocorra a partir do ensino sobre Ciências, o que inclui as dimensões procedimentais e atitudinais, englobando discussões acerca da natureza da ciência e dos valores do próprio conteúdo, além da dimensão conceitual. 
Our objective is to understand identity both as a nexus of multifiliation and as the reconciliation of the different forms of affiliation to social communities in order to understand how the (re) negotiation of meanings forges an identity nexus as a teacherresearcher who teaches about Sciences. In this qualitative investigation, we adopted life story as a research device, and the autobiographical narrative as the source for data production, which we analyzed according to the identity construct in practice proposed by Jean Lave and Etienne Wenger. To assist us in this analysis, we engage in the Alice's Adventures in Wonderland and Through the Looking Glass, highlighting the merit of the dialogue between science and art for the production of knowledge. Since we belong to various social communities, we (re) negotiate ways to be members in each of them, (de) constructing an identity of affiliation, as well as creating means of continuity between these communities through identity reconciliation.

Keywords: identity; negotiation of meanings; teacher-researcher; identity nexus; science teaching.

\section{Introdução}

'Ai, ai! Como tudo está esquisito hoje! E ontem as coisas aconteciam exatamente como de costume. Será que fui trocada durante a noite? Deixe-me pensar: eu era a mesma quando me levantei esta manhã? Tenho uma ligeira lembrança de que me senti um bocadinho diferente' (Carroll, 2013, p. 17, grifo do autor).

Alice estava aflita por ter passado por muitas mudanças, mas, como só podemos ser concebidas $/ \mathrm{os}^{3}$, mesmo, no devir, quem somos será sempre um grande enigma, pois,

Para dizer a verdade, que sabe o homem de si próprio? E poderia mesmo se perceber integralmente tal como é, como se estivesse exposto numa vitrina iluminada? A natureza não lhe haverá de esconder a maioria das coisas, mesmo sobre seu corpo, a fim de mantê-lo afastado das dobras de seus intestinos, da corrente rápida de seu sangue, das vibrações complexas de suas fibras, numa consciência orgulhosa e quimérica? (Nietzsche, 2013, p. 126).

Assim, no devir, Alice foi muitas, (des)construiu muitas identidades ao longo das experiências vivenciadas no País das Maravilhas e Através do Espelho, a ponto de, frequentemente, ter tido crises de identidade, como ocorreu ao negociar significados com a Lagarta:

'Quem é você?' perguntou a Lagarta. Não era um começo de conversa muito animador. Alice respondeu, meio encabulada: 'Eu... eu mal sei, Sir, neste exato momento... pelo menos sei quem eu era quando me levantei esta manhã, mas acho que já passei por várias mudanças desde então.' 'Que quer dizer com isso?' esbravejou a Lagarta. 'Explique-se!' 'Receio não poder me explicar', respondeu Alice, 'porque não sou eu mesma, entende?' 'Não entendo', disse a Lagarta (Carroll, 2013, p. 38, grifos do autor).

3 Ao longo do trabalho, optamos por nos referirmos ao gênero feminino antes do masculino. 
Essas crises de identidades podem ser entendidas como o duplo descentramento do sujeito, tanto de seu lugar no mundo social e cultural, quanto de si mesmo (Hall, 2006). Para o autor, isso ocorre porque as mudanças culturais experienciadas desestabilizam a posição que achamos ocupar como indivíduos sociais, modificando, do mesmo modo, nossas identidades pessoais e, dessa forma, a noção que temos de nós mesmos. Apesar disso,

Todos nós alguma vez na vida já tivemos vontade de escapar - seja de um trabalho estúpido e tedioso, de um relacionamento impossível, ou de um mundo no qual temos tão pouco controle sobre o que nos acontece. Talvez seja por razões como essas que nossa cultura tenha se tornado obcecada pela ideia de transcender os confins deste mundo em direção ao frescor de outro. Quer seja por meio de uma pílula vermelha, de uma sala secreta, de um espelho, ou de uma toca de coelho, não importa. Nós aceitamos (Irwin, \& Davis, 2010, p. 11, grifo dos autores).

E, dessa maneira, Alice, muito curiosa, desejou mergulhar em um novo mundo. Por isso, despencou pela toca do Coelho. Quando entramos em contato com novas culturas, adentramos em território desconhecido e não sabemos como nos relacionar com as/os demais, dado que nos faltam as referências que são compartilhadas pelas/os participantes desses contextos (Wenger, 1998):

A Lagarta foi a primeira a falar. 'De que tamanho você quer ser?' perguntou. 'Oh, não faço questão de um tamanho certo', Alice se apressou a responder; 'só que ninguém gosta de ficar mudando toda hora, sabe.' 'Eu não sei', disse a Lagarta. Alice não disse nada: nunca fora tão contestada em sua vida e sentiu que estava perdendo a paciência. 'Está satisfeita agora?' perguntou a Lagarta. 'Bem, gostaria de ser um pouco maior, Sir, se não se importasse', disse Alice. 'Oito centímetros é uma altura tão insignificante para se ter.' 'Pois é uma altura muito boa!' disse a Lagarta encolerizada, empinando-se enquanto falava (tinha exatamente oito centímetros de altura). 'Mas não estou acostumada a isso!' defendeu-se a pobre Alice num tom que inspirava pena (Carroll, 2013, p. 41, grifos do autor).

É nesse sentido que a posição que pensamos ocupar como indivíduos sociais é desestabilizada, ao (des)construirmos identidades por meio da confrontação com o desconhecido, o que é capaz de levar-nos à crise de identidade. Por outro lado, a identidade não é um objeto, um centro primordial da personalidade que já existe ou é adquirida em algum ponto de nossa vivência no mundo. Ela só pode ser pensada como algo que (re)negociamos constantemente ao nos relacionarmos com o mundo, em um misto [...] "do familiar e do alheio, do evidente e do misterioso, do transparente e do opaco" (Wenger, 1998, p. 153, tradução nossa).

Posto que participamos em diferentes comunidades sociais (trabalho, escola, família etc.), nos relacionamos com culturas distintas e (re)negociamos significados que (des)constroem uma identidade de participação, de afiliação a cada uma dessas comunidades (Wenger, 1998). Isto é, segundo o autor, reconhecemos algo de nós mesmos nas/os demais e somos reconhecidas/os pelas/os outras/os, produzindo uma 
experiência de participação, de identificação como membros dessas comunidades.

Nessa concepção de identidade situada na participação em comunidades sociais, não é possível pensar no indivíduo dissociado do ambiente sociocultural a que pertence. Por esse motivo, nossas identidades, mesmo que em um contexto de uma comunidade específica, não são apenas uma questão interna à comunidade, mas também uma questão da nossa posição e da posição de nossas comunidades no contexto de estruturas sociais mais amplas (Wenger, 1998).

Vivemos, em vista disso, múltiplas identidades (des)construídas como resultado da interação entre nós mesmos e os contextos sócio-históricos e culturais que nos cercam. Então, é possível dizer que a (des)construção identitária é um movimento contínuo de estar no mundo, uma relação de (re)negociação de significados com outras/ os que possibilita a constituição de quem somos.

Nessa perspectiva, a experiência de um significado não surge do nada nem é a execução mecânica de uma rotina ou um procedimento, não obstante, a (re)produção de pautas ao comprometer-nos em uma comunidade (Wenger, 1998). Por exemplo, o autor explica que podemos almoçar pela enésima vez com as/os mesmas/os amigas/os, no mesmo restaurante e, assim, tudo o que ocorre durante o almoço já foi vivenciado antes. Conhecemos o cardápio e podemos, até mesmo, pedir os mesmos pratos. Conhecemos muito bem nossas/os amigas/os e podemos conversar sobre as mesmas coisas. No entanto, durante o almoço, estamos produzindo uma nova situação, uma nova impressão, uma nova experiência. Ou seja, produzimos significados que ampliam, desviam, ignoram, (re)interpretam, modificam ou confirmam a história de significados de que fazem parte.

Da mesma maneira que Alice, experienciei ${ }^{4}$ mundos diversos, tais quais o de pesquisadora em Ciências Biológicas, o de professora que ensina sobre ciências e o de pesquisadora em Ciências Humanas. Contudo, esses não são mundos alheios. Ainda que sejam comunidades distintas, em que múltiplas identidades são (des)construídas mediante o elo constante entre o social e o individual, as diversas formas de participação nessas comunidades podem interagir, constituir-se mutuamente e exigir coordenação em um nexo de multifiliação a várias comunidades (Wenger, 1998).

Por essa razão, para Wenger, a noção de identidade supõe tanto a experiência de multifiliação como o trabalho de conciliação necessário para manter uma identidade entre limites de comunidades distintas. Isso porque nossos fragmentos de identidades não permanecem desconectados entre si - o que seria considerado patológico -, pelo contrário, buscamos conectar as diversas partes de nós mesmas/os, como peças de um quebra-cabeça que coexistem em um nexo identitário constituído por pontes que atravessam os panoramas das comunidades de que fazemos parte.

Foi desse modo que (des)construí-me uma professora-pesquisadora que ensina sobre ciências. Inicialmente, não optei pela licenciatura como formação, visto

$4 \mathrm{O}$ estudo refere-se às experiências vivenciadas pela primeira autora, que foram analisadas na investigação realizada por ambas as autoras. 
que ser professora era minha última opção profissional. Queria estudar a vida, ser uma pesquisadora da área de Ciências Biológicas. Porém, em minhas trajetórias, foi (des)construída, conjuntamente, a identidade de professora, e dividi-me entre ser pesquisadora da área de Ciências Biológicas e ser professora que ensina sobre ciências.

Em meio à participação nesses contextos, pensava: reconheço-me como pesquisadora em Ciências Biológicas ou como professora que ensina sobre ciências? Entretanto, será que era preciso, necessariamente, optar por um único eu, autêntico e verdadeiro? Segundo Wenger (1998), não, pois, como esclarecemos antes, vivemos múltiplas identidades (des)construídas ao (re)negociar significados em nossas experiências de afiliação a distintas comunidades sociais.

Dessa forma, embora algumas/uns professoras/es considerem que pesquisadoras/ es não têm as habilidades necessárias para ensinar (Richard, \& Bélanger, 2018), que uma/ um boa/bom pesquisadora/pesquisador não é, impreterivelmente, uma/um boa/bom professora/professor (Cruz, \& Barzano, 2014), e independentemente de não me imaginar, a princípio, uma professora, utilizava a identidade de pesquisadora - uma cientista para sentir-me segura em fazer conexões entre a ciência moderna e a tecnologia, ao ensinar sobre ciências às/aos estudantes, permitindo-me fornecer-lhes uma visão mais efetiva do que significa trabalhar como cientista (Silva, Oliveira, \& Souza, 2017).

De modo semelhante, Blomster, Venn e Virtanen (2014) constataram, em estudo realizado na Faculdade de Ciências Biológicas e Ambientais da Universidade de Helsinki, Finlândia, que a maioria das/os professoras/es que envolviam estudantes em pesquisas também eram pesquisadoras/es e referiam-se a si mesmas/os como tal. Essa instituição, cujo ambiente acadêmico é de pesquisa intensiva, tem o objetivo estratégico de que todas/os as/os professoras/es realizem pesquisa, e de que todas/os as/os pesquisadoras/es ensinem, sendo as/os estudantes consideradas/os membros da comunidade acadêmica.

Consequentemente, as/os autoras/s expõem que, como nessa instituição as atividades de pesquisa estão relacionadas tanto aos processos de ensino e aprendizagem, como às disciplinas específicas, isso sugere que as/os pesquisadoras/es ativas/os desempenham papéis importantes para o desenvolvimento e a aplicação da aprendizagem baseada em pesquisa, objetivo estratégico dessa universidade.

De acordo com Buxner (2014), participar em ambientes autênticos de pesquisas científicas pode mesmo fornecer às/aos professoras/es que ensinam sobre ciências experiências investigativas junto a cientistas, aumentando seu interesse pela ciência e, portanto, seu conhecimento do conteúdo científico e seu entendimento sobre a natureza da ciência e do processo de investigação na ciência, possibilitando, dessa maneira, o uso da pesquisa em sala de aula e o ensino mais efetivo desses fundamentos às/aos estudantes, melhorando seus desempenhos em Ciências.

Para Pekel e Akçay (2018), o envolvimento de professoras/es que ensinam sobre ciências com a pesquisa, tanto científica, como educacional, pode proporcionarlhes uma poderosa experiência de aprendizado para a educação em ciências das/ os estudantes, ajudando-as/os a aprenderem não apenas conteúdos de Educação 
Científica contemporânea, mas, igualmente, habilidades de raciocínio e investigação, contribuindo para que elas/es desenvolvam atitudes positivas em relação às ciências. Assim, por meio de processos de multifiliação a comunidades de pesquisa e de ensino, e de conciliação identitária, é possível a (des)construção de identidades como professoras/ es-pesquisadoras/es que ensinam sobre ciências.

Diferentes autoras/es (Blomster; Venn; Virtanen, 2014; Buxner, 2014; Cruz; Barzano, 2014; Fagundes, 2016; Impedovo; Khatoon Malik, 2016; Oliveira; Chapani, 2017; MEC, 2015; Pekel; Akçay, 2018; Richard; Bélanger, 2018; Zeichner, 1998) contextualizam e problematizam a ideia de professora/professor-pesquisadora/pesquisador sob pontos de vista diversos. Contudo, divergindo das concepções apresentadas, nesse estudo, o conceito é entendido, conforme já mencionado, como um nexo identitário.

Pensar em professoras/es-pesquisadoras/es como um nexo identitário nos obriga a olhar para nossas identidades não como simples sucessões no tempo, ou seja, não somos em determinados momentos professoras/es e em outros pesquisadoras/es. Ainda que experienciemos distintas trajetórias, cada uma delas se converte em parte das demais (Wenger, 1998), por isso, ao apresentarmos a perspectiva de professora/ professor-pesquisadora/pesquisador tencionamos encontrar uma identidade que possa conciliar nossas responsabilidades como professora/professor e como pesquisadora/ pesquisador. Dito de outra forma,

Fala-se hoje, com insistência, no professor pesquisador. No meu entender o que há de pesquisador no professor não é uma qualidade ou uma forma de ser ou de atuar que se acrescente à de ensinar. Faz parte da natureza da prática docente a indagação, a busca, a pesquisa. $\mathrm{O}$ de que se precisa é que, em sua formação permanente, o professor se perceba e se assuma, porque professor, como pesquisador (Freire, 1996, p. 32, nota).

A pesquisa está presente em diversas áreas do conhecimento, com distintas interpretações. No campo das ditas ciências duras (Biologia, Física e Química), a pesquisa está pautada em métodos criteriosos, no experimentalismo, na objetividade, em incansáveis análises estatísticas e no ideal de rigorosidade para a ciência, visando a captura e compreensão da realidade para a produção de conhecimento válido (Silva, Oliveira, \& Souza, 2018a).

Enunciado isto, evidentemente, não estamos assumindo que as Ciências Humanas seriam ciências moles, ou que há primazia das ciências duras sobre as Ciências Humanas. A pesquisa na área de Ciências Humanas, tal qual a realizada em Educação e em Ensino de Ciências, também é praticada com rigor e a partir de métodos criteriosos. Todavia, rigor é uma expressão problemática que pode ser interpretada de diferentes maneiras. Por exemplo, o excesso de rigidez na produção científica pode ser entendido como autoridade constituída, o que pode ser um sinal claro de falência do sistema, já que qualquer organismo rígido em demasia pode tender ao colapso estático (Galeffi, 2009).

Por outro lado, como sustentado pelo autor, rigor também pode representar a criticidade necessária para a interpretação de fatos e acontecimentos relacionados ao comportamento humano, uma qualidade da/o pesquisadora/pesquisador, um 
comportamento atitudinal que não diz respeito à organização exterior de passos e regras para a investigação científica. Nesse sentido, entendemos que a pesquisa em Ciências Humanas é muito criteriosa, visto que é preciso muito rigor para lidar com conhecimentos multifacetados, em que múltiplas dimensões se entrelaçam e, por esse motivo, dependem de interpretações nem sempre simples de serem concretizadas (Praia, 2012).

$\mathrm{Na}$ área educacional, a pesquisa tem sido apontada como uma maneira das/os professoras/es superarem a ideia da/o professora/professor técnica/o, que ensina com fins pragmáticos de reprodução de conhecimentos, para a compreensão de pessoa com potenciais criativos e críticos, capaz de atuar de forma competente e ética (Oliveira, \& Chapani, 2017).

Outros argumentos consistentes em favor do desenvolvimento de pesquisa pelas/ os professoras/es são: aumento da destreza para resolver problemas em sala de aula; elevação dos níveis de autonomia e de profissionalidade docente; maior motivação para o exercício de sua profissão; melhoria e desenvolvimento curricular, produção de currículos contra-hegemônicos (Oliveira, \& Chapani, 2017) e melhoria da prática reflexiva para o entendimento dos diferentes aspectos educacionais (Fagundes, 2016; Impedovo, \& Khatoon Malik, 2016).

As Diretrizes Curriculares Nacionais para a formação inicial em nível superior e para a formação continuada (MEC, 2015), considerando que a formação dos profissionais do magistério deve se dar em uma articulação entre a teoria e a prática, em que o ensino, a pesquisa e a extensão são indissociáveis, resolve, entre outras medidas, que as/os egressas/os dos cursos de formação em nível superior devem estar aptas/os a:

realizar pesquisas que proporcionem conhecimento sobre os estudantes e sua realidade sociocultural, sobre processos de ensinar e de aprender, em diferentes meios ambientalecológicos, sobre propostas curriculares e sobre organização do trabalho educativo e práticas pedagógicas, entre outros (MEC, 2015, artigo 8º, inciso XI).

Entretanto, essa perspectiva é permeada por dilemas, limitações e dificuldades para a inserção da pesquisa na formação e no trabalho docente, pois há a necessidade de desenvolvimento de habilidades específicas para a investigação, distintas da docência (Oliveira, \& Chapani, 2017). Por isso, a relação entre pesquisa e formação de professoras/ es é frutífera porque permite envolver as/os professoras/es no processo de produção de conhecimento, possibilita pesquisas mais direcionadas sobre práticas de ensino e leva a reflexões aprimoradas com base na análise de experiências (Impedovo, \& Khatoon Malik, 2016).

Dessa forma, a participação em pesquisas tem sido percebida, por algumas/ uns professoras/es, como uma maneira promissora de conectar seu desenvolvimento profissional com o conhecimento científico, como uma oportunidade única de construir pontes para superer a lacuna que percebem entre a prática docente e a pesquisa educacional (Richard, \& Bélanger, 2018).

No estudo realizado por esses autores, outras/os professoras/es concebem a 
participação em pesquisas não por seus efeitos nas práticas de ensino, mas sim por sua coerência com certo ideal de identidade profissional. Isto é, se participam de uma comunidade em que professoras/es envolvem-se em pesquisas, elas/es também comprometem-se com essa prática. Essa é uma forma de tornarem-se membros legítimos da comunidade (Wenger, 1998).

Portanto, como apresentado, visamos, nessa pesquisa, a compreensão da identidade tanto como nexo de multifiliação, quanto conciliação das distintas formas de afiliação a comunidades sociais (Wenger, 1998). Dado que a conciliação identitária não é um movimento harmonioso, livre de tensões (Wenger, 1998), posso ter vivido crises de identidade. Contudo, esse não é o foco desse trabalho, e sim a interpretação desse nexo identitário como professora-pesquisadora.

Assim, para ampliar o entendimento de estudos anteriores sobre processos de (des) construções identitárias (Silva, Oliveira, \& Souza, 2017, 2018a, 2018b), nessa pesquisa, refletimos criticamente sobre as experiências vivenciadas pela primeira autora, com o objetivo de entender como a (re)negociação de significados forja um nexo identitário como professora-pesquisadora que ensina sobre ciências.

Ou seja, por meio do aporte dos campos da filosofia, da sociologia e da pedagogia, o trabalho discute a relação entre as formações científica e pedagógica e suas consequências na (des)construção identitária de uma professora-pesquisadora que ensina sobre ciências, podendo contribuir para a área de pesquisa em Educação em Ciências, especialmente a respeito da formação docente de futuras/os professoras/ es que ensinam sobre ciências e biologia. Além disso, o estudo também pode ser uma importante contribuição para pensar o uso da narrativa autobiográfica como fonte para a produção de dados, uma perspectiva metodológica pouco utilizada na área.

\section{Trajetórias teórico-metodológicas do estudo}

Inicialmente, precisamos explicar que uma trajetória não diz respeito a um curso ou destino fixo, não é um caminho que possa ser previsto, senão um movimento contínuo que, embora tenha impulso próprio, é afetado pelos contextos socio-históricos e culturais, tendo coerência tal, através do tempo, que conecta o passado, o presente e o futuro (Delory-Momberger, 2011; Wenger, 1998). Dessa maneira,

Partindo da premissa de que os fenômenos sociais adquirem significados e representações, que são fruto das interpretações pessoais em que os sujeitos atribuem juízo de valor de acordo com seu contexto histórico-social, pensamos a pesquisa como forma de compreender e entender como tais fenômenos ocorrem nos contextos em que se inserem [...] (Oliveira, \& Chapani, 2017, p. 12).

Essa é uma pesquisa qualitativa, uma atividade situada cujo propósito é descrever e interpretar momentos e significados na vida das pessoas, permitindo a localização da/o pesquisadora/pesquisador no mundo e, do mesmo modo, dando visibilidade ao mundo, transformando-o em uma série de representações que buscam entender os significados que são conferidos a ele (Denzin, \& Lincoln, 2006). 
Para isso, adotamos como dispositivo de investigação a história de vida (Nóvoa, \& Finger, 1988), reconhecendo-a como arte formadora da existência (Pineau, 2006), uma revolução metodológica que possibilita dar legitimidade à subjetividade explicitada (Josso, 2006) para apreender quem somos, o que e como aprendemos ao longo da vida, quais as nossas experiências e que significados atribuímos ao vivido (Souza, 2006).

A produção da fonte de dados para esta pesquisa realizou-se mediante a narrativa autobiográfica, um veículo que permite contar a história da própria vida e, dessa forma, capturar a maneira como as pessoas se constituem e o sentido pessoal que é dado às experiências, no decorrer de uma dimensão temporal ou sequencial (Huberman, 2005).

Porém, a narrativa não é, simplesmente, uma sucessão de episódios dispersos, pelo contrário, organiza-se em tessitura, um encadeamento de eventos significativos para quem narra, no qual as intrigas são articuladas na experiência narrativa (Ricoeur, 1994). Para o autor, na tessitura da intriga, a ação tem um contorno, um limite e uma extensão, o que faz surgir o inteligível do acidental, o universal do singular, o necessário e verossímil do episódico. Por isso, ao produzir uma narrativa autobiográfica, criamos uma imagem de nós próprios, constituindo um meio de representar a própria existência, as escolhas efetuadas no decurso da vida e os valores que as guiaram (Catani, \& Vicentini, 2003).

Para a escrita da história, a segunda autora do estudo ajudou-me a explorar o potencial narrativo de fios temáticos transversais que haviam sido cortados, bem como provocou-me a dar esclarecimentos como especialista do meu eu (Schütze, 2010). Desse modo, a especificidade epistemológica da narrativa como forma de produção de conhecimentos adota um posicionamento crítico que [...] "centra-se no sujeito da formação e não apenas na formação em si mesma, abstraída de quem se forma" (Passeggi, 2016, p. 70). Por esse motivo, nesse modelo emergente de investigação, como sujeito da experiência, ao narrar pude refletir sobre mim mesma e sobre as experiências (re) negociadas na (des)construção de múltiplas identidades como professora-pesquisadora que ensina sobre ciências.

A análise da narrativa produzida foi realizada por intermédio de leituras sistemáticas do texto, tendo como referência o constructo de identidade na prática (Lave, \& Wenger, 1991; Wenger, 1998). Contudo, também utilizamos a bricolagem conceitual, isto é, a extração de conteúdos de áreas diversas para a produção de um conjunto de representações que nos ajudassem na interpretação das múltiplas realidades forjadas e na compreensão do nexo identitário como professora-pesquisadora que ensina sobre ciências.

Nessa pesquisa, a narrativa autobiográfica é tanto o fenômeno a ser investigado, quanto o método de investigação. Nesse sentido, o processo de investigação realizado pela primeira autora, como professora-pesquisadora, para além de ter sido uma forma de desenvolvimento profissional, foi uma forma de construção de conhecimentos com base nos dados produzidos diretamente pela participante envolvida no estudo, ao invés daqueles obtidos e analisados somente por pesquisadoras/es da academia, visando 
diminuir a lacuna existente entre a comunidade de pesquisadoras/es e a de professoras/ es (Richard, \& Bélanger, 2018), e ultrapassar a linha que divide a pesquisa acadêmica daquela realizada por professoras/es-pesquisadoras/es (Zeichner, 1998).

É elementar que não há neutralidade e distanciamento possível nesta investigação, mas,

[...] vendo-me no passado, vejo-me, de certa forma, como objeto - como "outrem" - mas, ainda mais do que o historiador, que conta o passado sempre do ponto de vista do presente, vejo o meu passado, vejome, não como foi, não como fui, mas como a que sou me mostra ter ele sido e ter eu sido (Soares, 2001, p 39, grifo da autora).

Convidamos Alice para auxiliar-me a olhar para o passado e a ver minhas experiências com a compreensão que tenho atualmente, mediando a reflexão crítica necessária ao estudo e ajudando-nos a dizer mais (Caine et al., 2016). Na interlocução com Alice, (re)inventamos outra relação com o conhecimento, através do diálogo entre ciência e arte, como uma forma de sermos mais humanos (Cachapuz, 2012). Não se trata, como sustenta Nietzsche (2013), de um aniquilamento da ciência, e sim de seu domínio, pois "o domínio da ciência já não se produz mais senão pela arte. Trata-se de juízos de valor sobre o saber e o saber-muito. Tarefa imensa e dignidade da arte nessa tarefa! Ela deve recriar tudo e recolocar totalmente sozinha a vida no mundo" (Nietzsche, 2013, p. 32).

Dessa maneira, resistimos às ideias da razão como uma capacidade para descobrir formas absolutas de conhecimento, da ciência e do método científico como o caminho supremo, universal e válido para a realidade e das verdades generalizadas e indubitáveis sobre o modo como as coisas realmente são (Crotty, 1998). Nesta concepção, não procuramos a verdade, [...] "mas a metamorfose do mundo nos homens [...] [e a] compreensão do mundo com a consciência de si” (Nietzsche, 2013, p. 96). O interesse é pelas metáforas retóricas e literárias, pela virada narrativa, pela narração de histórias, pela dúvida e pela recusa em privilegiar qualquer método ou teoria (Denzin, \& Lincoln, 2006).

\section{A identidade como multifiliação a comunidades sociais}

'Eu poderia lhes contar minhas aventuras... começando por esta manhẫ, disse Alice um pouco tímida; 'mas não adianta voltar a ontem, porque eu era uma pessoa diferente.' 'Explique isso tudo', disse a Tartaruga Falsa. (Carroll, 2013, p. 84).

Alice participou em diferentes comunidades ao longo de suas aventuras, o que levou-a a (re)negociar identidades de afiliação a cada uma delas. Por essa razão, no devir dos acontecimentos imprevistos, para se encaixar nessas comunidades ela foi muitas, testou-se e mudou a si própria por meio da comida e da bebida (Lloyd, 2010), a ponto de ter sido difícil, em muitos momentos, dizer exatamente quem era.

Como disse, anteriormente, a princípio não queria ser professora, porque a profissão docente era pouco valorizada - e, infelizmente, ainda é -, tanto em termos salarial quanto de status social. Essa crise associada à profissão docente, denunciada 
desde o final da década de 1970, teve como uma de suas causas a expansão do sistema público de ensino sem um correspondente investimento das verbas públicas destinadas à educação, levando à falta de condições materiais do trabalho docente e a uma progressiva perda salarial por parte das/os professoras/es (Diniz-Pereira, 2011).

Ademais, como o autor esclarece, a partir da segunda metade da década de 1980, as universidades brasileiras passaram a tratar com descaso as questões relativas ao ensino, havendo uma valorização da pesquisa em detrimento do ensino - uma separação entre teoria e prática e uma dicotomia entre bacharelado e licenciatura, no meio acadêmico, o que provocou um sentimento generalizado de que os cursos de formação de professoras/ es não eram uma boa opção para a graduação.

Um exemplo atual dessa secundarização do ensino, nas universidades, - embora avanços sejam evidenciados em algumas delas - diz respeito aos critérios utilizados para a promoção na carreira universitária, os quais ressaltam muito mais o número de publicações do que as avaliações feitas pelos discentes sobre dimensões da prática docente, reafirmando a valorização da pesquisa diante do ensino (Blomster, Venn, \& Virtanen, 2014; Cruz, \& Barzano, 2014).

A maneira pela qual as pessoas percebem as carreiras e a si próprias no contexto do trabalho, bem como as transformações por que passam os contextos sociais, interferem nas relações entre o indivíduo e o social e nas identidades sociais e profissionais e, por esse motivo, nos últimos anos, a diminuição da procura pela profissão de professora/ professor tem-se tornado objeto de muita preocupação (Tartuce, Nunes, \& Almeida, 2010).

Sendo assim, como havia certo glamour em ser pesquisadora, optei pelo bacharelado em Ciências Biológicas. No início da graduação, tentei participar em algum laboratório de pesquisa do Instituto de Biologia, não obstante, como tinha poucos conhecimentos na área, e o número de vagas para os estágios remunerados era bastante reduzido, não consegui nenhuma das vagas oferecidas. Então, fui fisgada pela docência, apesar de minha inserção na Educação ter ocorrido, naquele momento, apenas devido à possibilidade de obter uma remuneração, conciliando o trabalho com o estudo. Por isso,

[...] não negamos a importância da formação inicial institucional na "tecnologia" de produção do professor, mas não entendemos que apenas ela oferta/elabora esses saberes, ela é indispensável, mas é tecida em uma trajetória que abarca toda a história de vida do sujeito aprendente, o sujeito em formação para a docência (Cruz, \& Barzano, 2014, p. 124, grifo dos autores).

Desse modo, lecionei, como estagiária, em escolas públicas da Educação Básica até conseguir uma vaga para estagiar como pesquisadora em um dos laboratórios de pesquisa do Instituto de Biologia. Naquele momento, tive a certeza de que havia encontrado o que procurava: a pesquisa. Porém, como o valor da bolsa era baixo, não pude deixar de lecionar e, à vista disso, dividi-me entre a pesquisa e a docência durante toda a graduação.

No bacharelado, as discussões sobre processos de ensino e aprendizagem eram 
negadas/silenciadas, um campo blindado às influências explícitas das discussões sobre a formação docente, mesmo levando em consideração o sentido da formação da/o professora/professor-pesquisadora/pesquisador (Cruz, \& Barzano, 2014). Entretanto, como bem argumentam esses autores, [...] "os saberes pedagógicos estão ligados aos processos de educação em ciências e não podem ser desconsiderados no ensino das disciplinas científicas acadêmicas" [...] (Cruz, \& Barzano, 2014, p. 128).

Sem bases teóricas, fui aprendendo sobre a docência (re)negociando significados e decifrando o processo de reprodução da comunidade - a estruturação historicamente construída, os conflitos em curso, as atividades e as relações entre as/os profissionais - para entender as formas específicas de participação periférica legítima ao longo do tempo (Lave, \& Wenger, 1991). Nessas experiências de trabalho surgiram as demandas para o aprendizado de novos saberes (Cruz, \& Barzano, 2014) que conduziram-me a (des)construções identitárias.

Como a participação em comunidades socioculturais é sempre baseada na (re) negociação de significados entre pessoas que são membros de uma mesma comunidade, tanto a aprendizagem da docência quanto da pesquisa eram atividades situadas que tinham a prática social como fenômeno gerador e a participação periférica legítima como um descritor de engajamento crescente nessas práticas sociais (Lave, \& Wenger, 1991).

Segundo a autora e o autor, a aprendizagem na prática não é, simplesmente, um processo de transferência ou assimilação, pelo contrário, aprender, transformar e mudar estão interligados. Nesse sentido, o processo de reflexão, com base na autopercepção e nos pontos de vista de outras/os incorporadas/os à prática, foi útil para melhorar minhas habilidades como pesquisadora e como professora, e para (re)negociar significados (Impedovo, \& Khatoon Malik, 2016).

Dessa maneira, como novata, uma participante periférica, fui relacionandome com professoras/es e pesquisadoras/es veteranas/os, (re)negociando significados, mudando de perspectivas, transformando-me, abraçando as culturas das comunidades e encontrando maneiras de pertencimento a elas. Enfim, fui aprendendo nas práticas da pesquisa e da docência, engajando-me, movendo-me da periferia para uma plena participação nas comunidades e (des)construindo várias identidades em experiências de multifiliação (Lave, \& Wenger, 1991).

Depois que foi-me conferido o grau de bacharel em Ciências Biológicas, fui aprovada em um programa de mestrado em Ecologia e continuei na dita área dura de pesquisa, sendo predominantemente formada para a pesquisa e não para a docência, como tipicamente ocorre em programas de pós-graduação (Cruz, \& Barzano, 2014). No mesmo ano, ademais, passei a lecionar em um curso de Licenciatura em Biologia de uma faculdade particular, bem como continuei como professora da Educação Básica. Posteriormente, outras universidades e escolas da Educação Básica sucederam-se e, então, eu, que não queria ser professora, continuava dividindo-me entre o ensino e a pesquisa. 
Naquela época, algumas pessoas já me viam como professora, embora ainda fosse resistente a essa ideia. Talvez não estivesse engajada suficientemente nessa prática para uma (des)construção identitária docente, ou, possivelmente, a área de pesquisa em Ciências Biológicas me seduzisse e afetasse muito mais do que a prática docente. De fato, entendemos a identidade não somente como ela é vista pelas/os outras/os, mas, também, tal como uma pessoa percebe e vê a si mesma, em um sentido de imagem que é muito consistente e intimamente relacionado à concepção de motivação (Lave, \& Wenger, 1991).

Para Wenger (1998), nossas identidades são mesmo (des)construídas neste tipo de tensão existente entre nossa dedicação a diversas formas de afiliação e nossa capacidade de (re)negociar os significados que importam nesses contextos. Por isso, o autor explica que "podemos estar incluídos em uma comunidade ou excluídos dela e seguir identificando-nos com a situação nos dois casos" (Wenger, 1998, p. 191, tradução nossa).

Por esse ângulo, a despeito de ter adquirido experiência na área de educação em ciências, não estava incluída na comunidade de licenciadas/os, já que havia cursado o bacharelado, e, por esse motivo, não podia, a título de exemplo, participar de alguns concursos públicos para docentes. Desse modo, decidi cursar a Licenciatura em Biologia e, portanto, outras identidades foram (des)construídas.

Como participei de diversas disciplinas, não fui a mesma em todas elas. Uma vez que as/os professoras/es esperavam de nós, licenciandas/os, diferentes formas de participação nas aulas, (re)negociávamos diferentes significados, nos transformávamos quando saíamos de uma sala de aula e entrávamos em outra. Assim, somente nesse contexto, múltiplas identidades foram (des)construídas.

Na participação de práticas que conduziram-me à (des)construção de identidades docentes, fui membro de comunidades onde foram desenvolvidos projetos de pesquisa voltados às áreas de Educação e de Ensino de Ciências, o que me levou a desejar cursar o doutorado não mais nas Ciências Biológicas, e sim, na área de Ensino de Ciências. Dessa forma, preliminarmente, quis estudar a vida, contudo, a vida ofereceu-me o ensino, e, se no início considerava a docência enfadonha, porque havia um sentido dissociado de seus significados, isso foi se transformando na (re)negociação desses significados.

$\mathrm{Na}$ trajetória do doutorado, troquei experiências com outras/os pesquisadoras/ es das Ciências Humanas e fui provocada por novas visões de mundo, alheias àquelas forjadas na prática de pesquisa em Ciências Biológicas, pautada no experimentalismo, na objetividade e no rigor científico. Nessa dinâmica de mudança paradigmática, significados foram (re)negociados em um processo de aprendizagem no qual compreendi que o conhecimento é multifacetado, em que múltiplas dimensões se entrelaçam (Silva, Oliveira, \& Souza, 2018a).

À vista disso, mesmo que tivesse, inicialmente, (des)construído identidades de pesquisadora em Ciências Biológicas, posto que não queria ser professora, como as identidades são concebidas nas relações vivenciais entre as pessoas e os lugares, 
na participação em comunidades sociais (Lave, \& Wenger, 1991), ao (re)negociar significados com outras/os fui aprendendo, transformando-me, engajando-me e apreciando a profissão docente.

Logo, assim como o significado só existe ao negociá-lo, a identidade existe, não como um objeto em si mesmo, mas no trabalho constante de negociar o eu (Wenger, 1998). Dessa maneira, em minhas trajetórias, além da identidade de pesquisadora em Ciências Biológicas, também foram (des)construídas identidades de professora que ensina sobre ciências e de pesquisadora em Ciências Humanas.

\section{E agora, qual dessas setas devo seguir? ${ }^{5}:$ identidade como conciliação das distintas formas de afiliação a comunidades sociais}

Não era uma pergunta muito difícil, já que uma única estrada atravessava o bosque, e as duas setas apontavam para ela. 'Vou resolver a questão', disse Alice consigo, 'quando a estrada se dividir e elas apontarem rumos diferentes.' Mas isso não parecia provável. Andou e andou por um longo tempo, mas sempre que a estrada se dividia lá estavam as duas setas, apontando a mesma direção [...] (Carroll, 2013, p. 146).

Ao longo de suas aventuras, muitas vezes, Alice vê-se tendo que fazer escolhas. No entanto, ela vai testando-se, saboreando a vida em torno de si e aprende a combinação certa para se encaixar e ficar confortável consigo mesma (Lloyd, 2010).

Em minhas trajetórias profissionais, igualmente, havia muitas escolhas, diferentes setas, porém, como [...] "ser uma pessoa requer algum trabalho para reconciliar nossas diferentes formas de pertencimento” (Wenger, 1998, p. 159, tradução nossa), existia um único caminho a seguir para sentir-me confortável comigo mesma: ser professorapesquisadora que ensina sobre ciências.

Nesse percurso, visto que participava em diferentes comunidades, (re)negociava com outras/os significados que pareciam díspares e, por isso, (des)construía-me frequentemente. Dividia-me entre o ensino e a pesquisa, mundos paralelos para os quais, a princípio, não pensava em estabelecer pontes. E não pensava nisso porque o campo da Biologia era permeado de tensões, a exemplo de relações arbitrárias de poder que desencadeavam resistências e distanciavam as/os professoras/es-pesquisadoras-es em formação dos saberes pedagógicos (Cruz, \& Barzano, 2014). Consequentemente, em virtude de o ensino ser comumente entendido como um obstáculo à pesquisa (Blomster, Venn, \& Virtanen, 2014), não percebia que podia lançar mão de vertentes identitárias de pesquisadora e de professora em um mesmo contexto: a sala de aula.

Entretanto, apesar dos significados (re)negociados nas comunidades de que era membro parecerem díspares, eles tinham, de alguma forma, uma relação, o que permitia o trabalho de conciliação identitária. Assim, ao agregar as diferentes formas de participação nessas comunidades, principiei a aproximação entre a minha faceta de pesquisadora e a de professora, almejando eliminar a separação existente entre o mundo

5 O título da seção é o que Alice indaga-se ao divagar no bosque em que as coisas não têm nomes, capítulo 3 Insetos do Espelho - do livro "Através do Espelho e o que Alice encontrou por lá" (Carroll, 2013, p. 146). 
das/os professoras/es-pesquisadoras/es e o mundo das/os pesquisadoras/es acadêmicas/ os (Zeichner, 1998). Como a investigação era um grande desejo, passei a fazer da sala de aula um lócus de experimentação dos conhecimentos tácitos que tinha, e que iam sendo (re)significados a partir do cruzamento entre a minha prática docente e o que diziam os teóricos lidos.

Dado que trabalhava diariamente como cientista, nesse processo de (re) significação da prática docente, entendi que poderia planejar sequências didáticas investigativas que ajudassem as/os estudantes a compreenderem a natureza da ciência e o processo de investigação científica, melhorando o ensino em sala de aula.

Depois, como professora universitária, lecionei variadas disciplinas, tanto as ditas pedagógicas, como as consideradas específicas da área das Ciências Biológicas. Então, minha entrada na cultura universitária fomentou o progresso de meu processo formativo e a construção de saberes específicos (Cruz, \& Barzano, 2014) por meio da leitura e da (re)negociação de significados de distintas teorias, tanto das áreas de Ensino de Ciências e de Educação, quanto da área de Biologia, contribuindo para (re)significar e estabelecer relações entre os conhecimentos que tinha aprendido como pesquisadora em Biologia com conhecimentos das Ciências Humanas, possibilitando novos olhares para o ensino sobre ciências.

Como havia iniciado o trabalho de reconciliação identitária como professorapesquisadora, ao lecionar em universidades essas identidades não voltaram a se fragmentar. Pelo contrário, ao ensinar em disciplinas específicas das Ciências Biológicas, citando caso análogo, planejava aulas de campo para que as/os estudantes executassem projetos de investigação propostos por elas/es próprias/os, sob minha orientação. Ao final, eram aconselhadas/os a apresentarem os resultados de suas pesquisas em eventos dessa natureza ou em revistas científicas.

Dessa forma, como professora-pesquisadora que ensina sobre ciências, (re) negociava significados com as/os estudantes da Educação Básica a respeito desses conhecimentos, inclusive os procedimentos de pesquisa nas ciências. Com as/os graduandas/os, ora(re)negociava significados relacionados a conhecimentos pedagógicos da formação de professoras/es, ora conhecimentos de Biologia, ora conhecimentos da pesquisa em Biologia e, com colegas e professoras/es do bacharelado e do mestrado, (re) negociava conhecimentos da pesquisa em Biologia.

Desse modo, os conhecimentos relacionados a aspectos pedagógicos da formação de professoras/es, que trabalhava junto às/aos licenciandas/os, contribuíam para a minha própria formação como professora que ensina sobre ciências para estudantes da Educação Básica e, da mesma forma, (re)negociava com as/os licenciandas/os os significados das experiências que vivenciava na Educação Básica, utilizando-as como referências para ilustrar o que estava sendo discutido nas aulas.

Da mesma maneira, os conhecimentos específicos da pesquisa em Biologia, que discutia com colegas e professoras/es da graduação e do mestrado, eram elos fundamentais de (re)negociação de significados - tanto com as/os estudantes da 
Educação Básica como com as/os universitárias/os - para a conciliação identitária como professora-pesquisadora que ensina sobre ciências.

De acordo com Wenger (1998), os significados (re)negociados em uma prática podem, de fato, incorporar-se a práticas distintas por intermédio de conexões que fazemos entre elas. Ele explica que, nestas intermediações, tanto estabelecemos relações estreitas com outras/os participantes, (re)negociando os significados de nossa experiência de afiliação a cada uma das comunidades, como desenvolvemos maneiras idiossincráticas de participação mútua, o que nos leva à criação de diferentes identidades, mas, também, à conciliação entre elas.

Hoje, como doutora, pesquisadora em Ciências Humanas, essa é mais uma identidade incluída no nexo de distintos significados e formas de participação que é ser uma professora-pesquisadora que ensina sobre ciências. Esse processo de conciliar distintas formas de afiliação a comunidades sociais é mais complexo do que uma simples escolha entre opções ou crenças diferenciadas, pois é entendido como a negociação de uma identidade, o que exige esforço para encontrar maneiras de fazer com que nossas diversas formas de afiliação coexistam, com êxito ou através de uma luta constante (Wenger, 1998).

\section{Um final para a história}

Nessa pesquisa autobiográfica, nesse movimento de biografização, ou seja, na atividade de dar forma às experiências vividas, interpretá-las e dar-lhes um sentido, fui utilizando formas e estruturas de narrativa que refletem tanto as relações mantidas com a coletividade, como comigo mesma, em determinada época e em uma conjuntura histórica definida (Delory-Momberger, 2011).

Nesse processo de narrar, fragmentei-me, em um modo próprio de existência, em espectadora e personagem do espetáculo narrado, em objeto de reflexão e ser reflexivo (Passeggi, 2016). Portanto, ocupei-me, ao mesmo tempo, em explicar, em reexplicar, em viver e em reviver as histórias de outras formas.

Ser professora não era um desejo inicial, porém, em paralelo às experiências vivenciadas como pesquisadora em Ciências Biológicas, fui vivenciando a prática da profissão docente, permeada de situações incertas, conflituosas e singulares que exigiam de mim a (re)criação de soluções e a (re)construção de novas estratégias de ação para resolvê-las (Fagundes, 2016). Desse jeito, fui (des)construindo identidades, igualmente, como professora que ensina sobre ciências, além de outras, como a de pesquisadora em Ciências Humanas. Nessa atividade, fui aprendendo e buscando formas de conciliar essas identidades em um nexo identitário como professora-pesquisadora que ensina sobre ciências.

Ao analisarmos essas experiências, foi possível observar que, uma vez que pertencemos a várias comunidades sociais, (re)negociamos maneiras de ser um membro em cada uma delas, (des)construindo uma identidade de afiliação. Assim, ao participarmos em diferentes contextos, significados são (re)negociados em um elo entre o 
social e o individual, produzindo novas imagens constitutivas de nós, nas quais integramse outros significados, outras possibilidades e outras perspectivas (Wenger, 1998).

Então, nessa compreensão de identidade como nexo de multifiliação a comunidades, como sustenta Wenger, não é possível pensar no indivíduo dissociado do ambiente sociocultural a que pertence, e, por isso, vivemos múltiplas identidades, movimentos ininterruptos de estar no mundo. Contudo, embora haja diferenças significativas entre as comunidades de que participamos, criamos meios de continuidade entre elas, de agregar as distintas formas de afiliação, de conciliação identitária.

Ao compreender a identidade tanto como nexo de multifiliação, quanto conciliação das distintas formas de afiliação a comunidades sociais, obviamente, insistimos que o nexo identitário de professora-pesquisadora não é a mesma coisa do binômio professora e pesquisadora, porque há um compromisso de conciliação identitária, e também de natureza ética, de colocar a investigação a serviço da resolução de problemas das práticas docentes, ainda que a investigação não se esgote nessas práticas (Praia, 2012). Nesse sentido, entendemos a relevância de pesquisas realizadas por professoras/es a respeito de sua própria formação e de suas práticas, pois, tal como foi feito nesse estudo, ao refletir sobre suas experiências práticas, as/os professoras/es-pesquisadoras/es podem fortalecer sua intelectualidade e, além disso, produzir novos conhecimentos para o aperfeiçoamento do ensino.

Ao entrecruzarmos minhas histórias com as de Alice, buscamos a insubordinação, quer dizer, romper com a representação tradicional da pesquisa educacional (Barbosa, 2015) como uma forma de nos habituar com o estranho, com a/o outra/o, e um modo de repensar o fazer científico, já que rigor e poesia não são dimensões incompatíveis.

Dessa maneira, este estudo não apresenta conhecimentos (des)construídos pela razão, na busca de verdades generalizáveis, não obstante, possibilidades de uso de narrativas, de histórias e de metáforas retóricas e literárias para o diálogo entre arte e ciência, como formas de compreender os mundos em que vivemos, de sermos mais humanos e, como bem dito por Nietzsche (2013), de recolocar a vida no mundo. Por esse motivo, agradecemos a Alice, visto que, por meio de suas histórias entendemos que podemos ser muitas/os nos múltiplos mundos a que pertencemos.

\section{Agradecimentos}

O presente trabalho foi realizado com apoio da Coordenação de Aperfeiçoamento de Pessoal de Nível Superior - Brasil (CAPES) - Código de Financiamento 001.

\section{Referências}

Barbosa, J. C. (2015). Formatos insubordinados de dissertações e teses na Educação Matemática. In B. S. D’ambrosio, B. S., \& C. E. Lopes (Orgs.), Vertentes da subversão na produção científica em educação matemática (pp. 347-367). Campinas, SP: Mercado de Letras. 
Blomster, J., Venn, S., \& Virtanen, V. (2014). Towards Developing a Common Conception of Research-Based Teaching and Learning in an Academic Community. Higher Education Studies, 4(4), 62-75. http://dx.doi.org/10.5539/hes.v4n4p62

Buxner, S. R. (2014). Exploring How Research Experiences For Teachers Changes Their Understandings Of The Nature Of Science And Scientific Inquiry. Journal of Astronomy \& Earth Sciences Education, 1(1), 53-68.

Cachapuz, A. F. (2012). Do ensino das ciências: seis ideias que aprendi. In A. F. Cachapuz, A. M. P. D. Carvalho, \& D. Gil-Perez (Orgs.), O ensino das ciências como compromisso científico e social: os caminhos que percorremos (pp. 11-32). São Paulo, SP: Cortez.

Caine, V., Murphy, M. S., Estefan, A., Clandinin, D. J., Steeves, P., \& Huber, J. (2016). Exploring the Purposes of Fictionalization in Narrative Inquiry. Qualitative Inquiry, 23(3), 215-221. https://doi.org/10.1177/1077800416643997

Carroll, L. (2013). Alice: Aventuras de Alice no País das Maravilhas \& Através do Espelho. Tradução de Maria Luiza X. de A. Borges. 2. ed. Rio de Janeiro: Zahar.

Carvalho, A. M. P. (2004). Critérios Estruturantes para o Ensino das Ciências. In A. M. P. Carvalho (Org.), Ensino de ciências: unindo a pesquisa e a prática (pp. 1-17). São Paulo, SP: Pioneira Thomson Learning.

Catani, D. B., \& Vicentini, P. P. (2003). "Minha vida daria um romance": lembranças e esquecimentos, trabalho e profissão nas autobiografias de professores. In A. C. V. Mignot, \& M. T. S. Cunha (Orgs.), Práticas de memória docente (pp. 149-166). São Paulo, SP: Cortez.

Crotty, M. (1998). The foundations of social research: Meaning and perspective in the research process. London: Sage.

Cruz, E. P., \& Barzano, M. A. L. (2014). Saberes docentes: um olhar para uma dimensão não exigida nas trajetórias de professores-pesquisadores do curso de Licenciatura em Ciências Biológicas. Investigações em Ensino de Ciências, 19(1), 117-139.

Delory-Momberger, C. (2011). Fundamentos epistemológicos da pesquisa biográfica em educação. Educação em Revista, 27(1), 333-346. https://doi.org/10.1590/S010246982011000100015

Denzin, N. K., \& Lincoln, Y. S. (2006). Introdução: A disciplina e a prática da pesquisa qualitativa. In N. K. Denzin, \& Y. S. Lincoln (Orgs.), O planejamento da pesquisa qualitativa: Teorias e abordagens (pp. 15-41). Tradução de Sandra Regina Netz. 2. ed. Porto Alegre, RS: Artmed.

Diniz-Pereira, J. E. (2011). O ovo ou a galinha: a crise da profissão docente e a aparente falta de perspectiva para a educação brasileira. Revista Brasileira de Estudos Pedagógicos, 92(230), 34-51. http://dx.doi.org/10.24109/2176-6681.rbep.92i230.541 
Fagundes, T. B. (2016). Os conceitos de professor pesquisador e professor reflexivo: perspectivas do trabalho docente. Revista Brasileira de Educação, 21(65), 281-298. http://dx.doi.org/10.1590/S1413-24782016216516

Freire, P. (1996). Pedagogia da autonomia: saberes necessários à prática educativa. 25 . ed. São Paulo: Paz e Terra.

Galeffi, D. A. (2009). O rigor nas pesquisas qualitativas: uma abordagem fenomenológica em chave transdisciplinar. In R. S. Macedo, D. A. Galeff, \& A. Pimentel, Um rigor outro sobre a qualidade na pesquisa qualitativa: educação e ciências humanas (pp. 13-74). Salvador, BA: EDUFBA.

Hall, S. (2006). A identidade cultural na pós-modernidade. Tradução de Tomaz Tadeu da Silva e Guacira Lopes Louro. 11. ed. Rio de Janeiro: DP\&A.

Huberman, M. (2005). Trabajando con narrativas biográficas. In H. Mcewan, \& K. Egan (Comps.), La narrativa en la enseñanza, el aprendizaje y la investigación (pp. 183-235). Buenos Aires, AR: Amorrortu.

Impedovo, M. A., \& Khatoon Malik, S. (2016). Becoming a Reflective In-service Teacher: Role of Research Attitude. Australian Journal of Teacher Education, 41(1), 100-112.

Irwin, W., Davis, R. B. (2010). Introdução: Você está atrasado para um importante encontro marcado. In W. Irwin, \& R. B. Davis, Alice no País das Maravilhas e a filosofia: cada vez mais e mais curioso (pp. 11-12). Tradução de Camila Zanon. São Paulo, SP: Madras.

Josso, M. C. (2006). Os relatos de histórias de vida como desvelamento dos desafios existenciais da formação e do conhecimento: Destinos sócio-culturais e projetos de vida programados na invenção de si. In E. C. Souza, \& M. H. M. B. Abrahão (Orgs.), Tempos, narrativas e ficções: A invenção de si (pp. 21-40). Porto Alegre, RS: EDIPUCRS, EDUNEB.

Lave, J., \& Wenger, E. (1991). Situated learning: legitimate peripheral participation. Cambridge: Cambridge University Press.

Lloyd, M. S. (2010). Alice rebelde: uma perspectiva feminista de algumas aventuras no País das Maravilhas. In W. Irwin, \& R. B. Davis, Alice no País das Maravilhas e a filosofia: cada vez mais e mais curioso (pp. 15-24). Tradução de Camila Zanon. São Paulo, SP: Madras.

MEC (2015). Diretrizes Curriculares Nacionais para a formação inicial em nível superior (cursos de licenciatura, cursos de formação pedagógica para graduados e cursos de segunda licenciatura) e para a formação continuada. Brasília: Conselho Nacional de Educação. Recuperado em 27 de setembro de 2018, de http://portal.mec.gov.br/docman/agosto2017-pdf/70431-res-cne-cp-002-03072015-pdf/file

Nietzsche, F. W. (2013). O Livro do Filósofo. Tradução de Antonio Carlos Braga. São Paulo: Escala. 
Nóvoa, A., \& Finger, M. (1988). O método (auto)biográfico e a formação. Lisboa: MS/ DRHS/CFAP.

Oliveira, D. X., \& Chapani, D. T. (2017). A pesquisa na formação em exercício de professores de Ciências e Biologia. Ensaio: Pesquisa em Educação em Ciências, 19,1-19. http://dx.doi.org/10.1590/1983-21172017190107

Passeggi, M. C. (2016). Narrativas da experiência na pesquisa-formação: do sujeito epistêmico ao sujeito biográfico. Roteiro, 41(1), 67-86. http://dx.doi.org/10.18593/r. v41i1.9267

Pekel, F. O., \& Akçay, S. (2018). Are science teachers really aware of the importance of educational research? European Journal of Education Studies, 4(3), 196-214. https://doi. org/10.5281/zenodo.1199533

Pineau, G. (2006). As histórias de vida como artes formadoras da existência. In E. C. Souza, \& M. H. M. B. Abrahão, Tempos, narrativas e ficções: a invenção de si (pp. 41-59). Porto Alegre, RS: EDIPUCRS/EDUNEB.

Praia, J.F. (2012). Contributo para uma leitura possível de um percurso profissional. In A. F. Cachapuz,A.M.P.Carvalho, \&D.Gil-Pérez,(Orgs.),Oensinodasciênciascomocompromisso científico e social: os caminhos que percorremos (pp. 53-74). São Paulo, SP: Cortez.

Richard, V, \& Bélanger, M. (2018). Accepting research: Teachers' representations of participation in educational research projects. International Journal of Educational Methodology, 4(2), 61-73. http://dx.doi.org/10.12973/ijem.4.2.61

Ricoeur, P. (1994). Tempo e narrativa (tomo 1). Tradução de Constança Marcondes Cesar. Campinas: Papirus.

Schütze, F. (2010). Pesquisa biográfica e entrevista narrativa. In W. Weller, \& N. Pfaff (Orgs.), Metodologias da Pesquisa Qualitativa em Educação: Teoria e Prática (pp. 210222). Petrópolis, RJ: Vozes.

Silva, P. P., Oliveira, A. M. P., \& Souza, E. C. (2017). Parecia mesmo um grupo estrambótico: (re)negociações identitárias na participação em comunidades de prática. Ensaio: Pesquisa em Educação em Ciências, 19, 1-17. http://dx.doi.org/10.1590/198321172017190134

Silva, P. P., Oliveira, A. M. P., \& Souza, E. C. (2018a). "Mais parece um saca-rolha que um caminho!": identidades contingentes de pesquisadora em ciências biológicas a pesquisadora em ciências humanas. Revista Brasileira de Educação, 23, 1-19. http:// dx.doi.org/10.1590/S1413-24782018230092

Silva, P. P., Oliveira, A. M. P., \& Souza, E. C. (2018b). E agora, quem sou eu? Vou me lembrar, se puder! Estou decidida!: (des)construções identitárias de uma professora que ensina sobre Ciências. Educação em Revista, 34, 1-22. http://dx.doi.org/10.1590/01024698183635 
Soares, M. (2001). Metamemória-memórias: travessia de uma educadora. 2. ed. São Paulo: Cortez.

Souza, E. C. (2006). A arte de contar e trocar experiências: reflexões teórico-metodológicas sobre história de vida em formação. Revista Educação em Questão, 25(11), 22-39.

Tartuce, G. L. B. P., Nunes, M. M. R., \& Almeida, P. C. A. (2010). Alunos do Ensino Médio e atratividade da carreira docente no Brasil. Cadernos de Pesquisa, 40(140), 445-477.

Zeichner, K. M. (1998). Para além da divisão entre professor-pesquisador e pesquisador acadêmico. In C. M. Geraldi, D. Fiorentini, E. M. Pereira (Orgs.), Cartografia do trabalho docente: professor(a)-pesquisador(a) (pp. 207-236). Campinas, SP: Mercado de Letras/ ABL.

Wenger, E. (1998). Communities of practice: Learning, meaning, and identity. Cambridge: Cambridge University Press.

Patrícia Petitinga Silva

[1] https://orcid.org/0000-0002-7724-5458 Universidade Federal da Bahia Instituto de Biologia Salvador, Bahia, Brasil patpetitinga@yahoo.com.br

Andréia Maria Pereira de Oliveira

[ำ https://orcid.org/0000-0002-8011-5179 Universidade Federal da Bahia

Faculdade de Educação

Salvador, Bahia, Brasil ampo@ufba.br

Subbmetido em 05 de janeiro de 2019

Aceito em 09 de setembro de 2019

Publicado em 18 de outubro de 2019 